\title{
Formulation of Areca Nut Tablet using Cassava Starch and Swamp Taro Starch as Disintegrant: A Comparative Study
}

\author{
Aljon Victor G. Nibalvos*, Esther R. Bañar, Edmundo A. Campoto, Maricar T. Obina, \\ Delbert A. Dala, Loida A. Rapada, Lylah Daisy A. Acorin, Debbie Joyce R. Voloso, \\ Jenny Rose U. Kruse, Rey Niel C. Salac, Noel Amit and Neil Alejandro A. Pinarok \\ Eastern Samar State University, Borongan City, Eastern Samar, Philippines; aljonvictorgalitnibalvos@gmail.com, \\ banar50esther@gmail.com,edmundocampoto@yahoo.com,maricar_obina@yahoo.com,dadessu@yahoo.com, \\ loidarapada2@yahoo.com,dacorin@yahoo.com, debbiejoycevoloso@gmail.com,jhenjer77@yahoo.com.ph, \\ salacreyniel@gmail.com,namit@yahoo.com,napinarok@yahoo.com
}

\begin{abstract}
Objectives: This study formulated a tablet using cassava and swamp taro starch as disintegrant and areca nut as active anthelmintic agent; the tablet was manually compacted and its physical, mechanical and disintegrating properties were determined. Methods/Statistical Analysis: Experimental design was utilized wherein two tablet formulations were subjected to physical, mechanical and disintegrating tests. Physical properties include color, density, odor, $\mathrm{pH}$ and solubility; mechanical property of the tablet was also tested in terms of hardness and friability; and disintegrating property was determined using simulated gastric fluid and simulated intestinal fluid. T-test was used to determine significant difference in terms of disintegration of the two tablets using IBM SPSS version 21. Findings: Results showed that the color and odor of both tablets are brown with white specks and odorless, respectively. Both tablets were insoluble to organic and inorganic solvents, but are slightly soluble to alcoholic medium; moreover, both tablets possess the same pH of 6.0. Friability tests showed high friability and a low compressive strength or hardness. Further statistical computations in terms of disintegration showed that cassava starch-based tablet is more rapid in disintegrating than swamp taro starchbased tablet regardless of simulated fluid. Application/Improvements: These findings indicate that cassava starch can be used as disintegrant, also this also highlights that direct compaction or manual compaction method of tableting gives a tablet lower hardness and higher friability. This study suggests cassava starch is more suitable as disintegrant than swamp taro, and that both starches can be used for veterinary drug development.
\end{abstract}

Keywords: Areca Nut, Cassava, Disintegrant, Starch, Tablet, Swamp Taro

\section{Introduction}

Tablets are compacted or compressed form of drugs added with various substances that play a specific role for the drug to function effectively. Along with the manufacture of tablets are disintegrant. Now, what is a disintegrant? Disintegrants are substances routinely included in tablet formulations and in many hard shell capsule formulations to promote moisture penetration and dispersion of the matrix of the dosage form in dissolution fluids toexpose primary drug particles. Most disintegrants used in tablet formulation are modified cellulose, crosslinked polyvinylpyrrolidone and modified starch or sodium starch gylcolate. These disintegrants are also known as super disintegrants 1 .

Reca catechu L. also known as Betel Nut/Areca Nut or Bunga in Waray-waray dialect is a tree belonging to the Family Palmaceae, relative of coconuts. It is primarily

*Author for correspondence 
used as a major component in betel quid chewing ( $\mathrm{Ma}$ $m a$ ) where most Samareños enjoy as it is said to strengthen teeth and gums. But there is still one marvel in the Betel Nut, it is an effective dewormer which is supported by the fact that most people in Eastern Samar use small pieces of Areca Nut to deworm their poultry animals and further, it is widely used in Eastern Samar primarily as a dewormer.

Anthelmintic drug discovery has a poor relation of the pharmaceutical industry, it is for the reason that the nations which suffer most from these tropical diseases have little money to invest in drug discovery or therapy, moreover it comes as no surprise therefore that the drugs available for human treatment were first developed as veterinary medicines, thus, a pitifully small repertoire of chemotherapeutic agents available for treatment ${ }^{2}$.

With this in mind, the researchers sought to formulate an anthelmintic tablet using Areca nut as the primary drug component while using the starches from cassava and swamp taro to have a newer source of anthelminthic drug added with plant ingredients and promote the use of plant starch as component for drug manufacture in the pharmaceutical industry.

\section{Materials and Methods}

Experimental research design was utilized by this study wherein two (2) formulations of Areca nut tablet using two different starches as disintegrant was utilized to determine its disintegrating property. This study was conducted at Eastern Samar State University, Borongan campus. Areca nuts were collected from the localities of Eastern Samar. The most common variety of Areca (red variety) was used in this study.

5 kilograms of Areca nuts were collected from areas where the said plant was available. The nuts were taken out and chopped to smaller granules. The granular nuts were subjected to dehydration by drying the areca nuts under the sun for 8 hours a day for 2 days. The dried nuts were then pulverized using a Mortar and Pestle, and the powdered nuts were then collected and used for formulating the standard $100 \mathrm{mg} / 500 \mathrm{mg}$ standard dosage as illustrated in the "Anthelminthic Drug Administration" Presentation for helminthes.

A total of $10 \mathrm{~kg}$ Cassava and $10 \mathrm{~kg}$ Swamp Taro crops were brought from the market of Borongan City and from the farmers in San Julian, Eastern Samar. The starches were collected by rasping, pulping and extracting the root crops. The wet starches were physically modified by sun drying for 8 hours a day for 5 days. Afterwards, the dried starches were powderized using Mortar and Pestle and sifted for consistency of powder. These powder of cassava and swamp taro was then used as disintegrant for the formulation of the $100 \mathrm{mg} / 500 \mathrm{mg}$ standard dosage tablet $\underline{3}$.

Method that was utilized in this part was taken from the lesson, PHAR 535: Pharmaceutics: Tablets and Capsules: Design and Formulation 1 . The following procedure was followed: All ingredients for the formulation of the Areca nut tablet were simply mixed thoroughly together until a uniform consistency was achieved. The mixed ingredients were then compressed using a tablet press. After compression, the tablets formed were collected and was tested for its physical, mechanical and disintegrating capacity 1 .

A standard $100 \mathrm{mg}$ dosage formulation was used in this study from areca nut using Cassava Starch and Swamp Taro Starch as disintegrant as seen in Figure 1.

\begin{tabular}{cc}
\hline Composition & Standard 100 mg Dosage \\
\hline Drug & $100 \mathrm{mg}$ \\
Filler & $347.5 \mathrm{mg}$ \\
$\begin{array}{c}\mathbf{1 0} \% \\
\text { Disintegrant }\end{array}$ & $50 \mathrm{mg}$ \\
$\begin{array}{c}\text { (Cassava/Swamp } \\
\text { T aro Starch) } \\
\text { Lubricant }\end{array}$ & $2.5 \mathrm{mg}$ \\
T otal & $\mathbf{5 0 0 ~} \mathbf{m g}$ \\
\hline
\end{tabular}

Figure 1. Tablet formulation using Direct Compaction Method.

Both tablets formulated using cassava and swamp taro starches were subjected to physical analysis in term of their color, density, odor, $\mathrm{pH}$ and solubility, the following procedures were utilized to assess its physical properties: The color of the manufactured tablet was determined using the sense of sight of five (5) random respondents which served as basis for determining the color of the tablet formed. Color determination was done to both tablets manufactured with cassava and swamp taro starches. Standard method for determining the density of 
the $500 \mathrm{mg}$ tablet, the tablet was submerged in a $5 \mathrm{~mL}$ graduated cylinder and its displacement was recorded. The volume of displacement was then used to determine the density of the tablet by means of the following equation: Density $=$ Mass/Volume. The procedure was repeated thrice. The odor of the manufactured tablet was determined using the olfactory sense of five (5) random respondents which served as basis for determining the odor of the tablet formed. Odor determination was done to both tablets manufactured with cassava and swamp taro starches. The $\mathrm{pH}$ of the tablets was determined using a $\mathrm{pH}$ paper. Tablets of different disintegrants were immersed in neutral distilled water and stirred. Then, the $\mathrm{pH}$ level of the solution was determined by submerging the $\mathrm{pH}$ paper into the solution and comparing the change in $\mathrm{pH}$ paper color to the $\mathrm{pH}$ indicator. The $\mathrm{pH}$ was recorded and the procedure was repeated thrice. Solubility of the tablets of varying disintegrant was determined using 5 different solvents. The solvents will be as follows: Distilled Water, $10 \% \mathrm{HCl}, 10 \% \mathrm{NaOH}$, Ethanol and Chloroform. Then, 1 whole tablet was submerged into the different solvents without applying external force or change in temperature, and the solubility of the (Table 1) tablet as observed which is either soluble or insoluble. The procedure was repeated thrice to all solvents.

Mechanical strength of the two formulated tablets was determined in terms of their Friability and Hardness. The following procedure will be utilized: Friability is the property of a tablet to resist abrasion and chipping, the friability of the manufactured tablets will be determined using a mechanical Friabilator, five tablets were weighed, and their total weight was recorded. The tablets were then inserted into the friabilator and it was rotated manually at 42 rounds per minute for 1 minute. After the rotation, the tablets were then weighed again and the $\%$ weight loss due to chipping, abrasion and erosion is reported as \% Friability using \% Friability $=\frac{W_{0}-W_{f}}{W_{0}} \times 100$, where $W_{o}$ is the initial weight and $W_{f}$ is the final weight. Hardness can be defined as the breaking strength of tablets. In this test, the hardness was computed by using the equation below $\mathrm{S}=\mathrm{PA}$, where $\mathrm{S}$ is the compressive strength, $\mathrm{P}$ is the maximum load applied to the specimen and $\mathrm{A}$ is the area. The test was repeated thrice.

Disintegrating property is considered to be the state of a tablet to which any residue, except fragments of insoluble coating, remaining on the screen is a soft mass having no palpably firm core. The new designed Disintegration Test Apparatus for Rapidly Disintegrating Tablets (RDTs) assembled by Hoashi, Tozuka and Takeuchi (2013) was used for testing the disintegration time of the processed tablets using Swamp Taro and Cassava Starch as disintegrant with slight modifications. The apparatus is composed of upper and lower meshes, a flow pump and a funnel-like weight in which the upper mesh is located (total weight is $10.0 \mathrm{~g}$ ), the apparatus was further modified in which instead of water as disintegration test solution, a standard Simulated Gastric Fluid and Simulated Intestinal Fluid solutions were used as published by the Ministry of Health, Canada (2003). The disintegration test solutions were heated at a range of $40.6^{\circ} \mathrm{C}$ to $41.7^{\circ} \mathrm{C}$ to further simulate body temperature of poultry fowls and dropped above the tablet sample using a separatory funnel as flow pump. The flow rate and drop height was set at $0.1 \mathrm{~mL} / \mathrm{sec}$ at $8 \mathrm{~cm}$, respectively. Disintegration time of the tablet samples was recorded when total disintegration of the same was complete and completion of disintegration is determined by the upper mesh contacting the bottom mesh.

Table 1 . Solubility characteristics of the 2 tablets

\begin{tabular}{|c|c|c|c|c|c|c|}
\hline \multirow{2}{*}{ Tablet Samples } & \multirow{2}{*}{ Trials } & \multicolumn{5}{|c|}{ Solvents } \\
\hline & & Alcohol & Chloroform & Water & $10 \% \mathrm{NaOH}$ & $10 \% \mathrm{HCl}$ \\
\hline \multirow{3}{*}{ Swamp Taro Starch-Based Tablet } & 1 & SS & IS & IS & IS & IS \\
\hline & 2 & SS & IS & IS & IS & IS \\
\hline & 3 & SS & IS & IS & IS & IS \\
\hline \multicolumn{2}{|l|}{ Interpretation } & SS & IS & IS & IS & IS \\
\hline \multirow{3}{*}{ Cassava Starch-Based Tablet } & 1 & SS & IS & IS & IS & IS \\
\hline & 2 & SS & IS & IS & IS & IS \\
\hline & 3 & SS & IS & IS & IS & IS \\
\hline \multicolumn{2}{|l|}{ Interpretation } & SS & IS & IS & IS & IS \\
\hline
\end{tabular}

Legend: SS-slightly soluble, IS-Insoluble 
All measurements were performed three times, and the mean disintegration time represents the average.

The Sample Mean Values (mean \pm ) for $\mathrm{pH}$, density, friability, hardness and disintegrating property were manually calculated using equation 3 . IBM $^{\oplus}$ SPSS $^{\oplus}$ Statistics Version 21 was used to determine the significant difference of the two tablets in terms of their disintegrating property using T-test.

\section{Results and Discussion}

Starch samples were taken from two (2) different types of root crops; Swamp Taro and Cassava. The starches were collected by rasping, pulping and extracting the root crops. The wet starches were physically modified by sun drying for 8 hours a day for 5 days. Afterwards, the dried starches were powderized using Mortar and Pestle. The Areca nut was subjected to dehydration by drying the areca nuts under the sun for 8 hours a day for 2 days. The dried nuts were then pulverized using a Mortar and Pestle. Then, the powdered starches were used as disintegrant, and the Areca Nut powder together with some key reagents in the production of Areca Nut tablet was also used. Manual Compaction Method was used as means of producing Areca Nut Tablet as Anthelminthic using a combination of a die, an upper punch, and a lower punch with a radius of $0.484 \mathrm{~mm}$.

The produced tablet using two (2) different starch were subjected to experimental tests to determine its physical, mechanical and disintegration property, and after thorough experimentation, the following results were obtained:

\subsection{Physical Examination of the Tablet}

As seen from the Table 2, as perceived by the respondents, the distinguishing color of both tablets was brownish with white specks, and the odor of both tablets according to the respondents is also odorless. The color if the tablet is due to the presence of $100 \mathrm{mg}$ Areca nut powder which is the active ingredient of the tablet. The odor is due to some inert substances such as sucrose as filler, and stearic acid as lubricant that neutralizes the odor of the tablet. The dry almond/coffee/cacao odor as perceived by some respondents is due to the aromatic odor of the areca nut powder. An average of $1.39 \mathrm{~g} / \mathrm{cc}$ and $1.34 \mathrm{~g} / \mathrm{cc}$ for density was observed to the Swamp Taro-based tablet and Cassava-based tablet, respectively. This result signifies that the produced tablets have dense consistency. But in terms of their $\mathrm{pH}$, both tablets possess $6.0 \mathrm{pH}$ level which means that both the tablets starched with either swamp taro or cassava is acidic. Table 3 shows that only in alcohol are that the two tablet formulations are slightly soluble which means that, the tablets is slightly affected by highly polar solvents, water is a polar solvent but its polarity does not affect the dense consistency of the tablets. It can be noted that this result is observed in which the tablets were only submerged into the solvents, but there was no application of external forces that can dissociate the tablets such as stirring or agitation of the liquid material. Further observation of the table signifies that the tablets are insoluble regardless of the solvents origin, whether an acid, a base, an organic or inorganic substance.

The average friability of the two tablets has a varying difference of $\pm 3.88 \%$. This suggests that the produced tablets are prone to abrasion and chipping. Moreover,

Table 2. Color and odor characteristic of the 2 tablets

\begin{tabular}{|c|c|c|c|c|}
\hline \multirow{4}{*}{ Respondent } & \multicolumn{4}{|c|}{ Starch-based Tablets } \\
\hline & \multicolumn{3}{|c|}{ Swamp Taro-Based Tablet (STSBT) } & Cassava-Based Tablet (CSBT) \\
\hline & \multicolumn{4}{|c|}{$\begin{array}{r}\text { Parameters } \\
\end{array}$} \\
\hline & Color & Odor & Color & Odor \\
\hline 1 & Brownish & Milky Odor & Light Brown & Fishy \\
\hline 2 & Brown with White Specks & Odorless & Brown and White Specks & Odorless \\
\hline 3 & Beige & Odorless & Brown and White Specks & Odorless \\
\hline 4 & Chocolate Brown with white Specks & $\begin{array}{l}\text { Dry Cacao/ } \\
\text { Coffee Odor }\end{array}$ & Brown and White Specks & Dry Almond Odor \\
\hline 5 & Brownish with White Specks & Odorless & Brown and White Specks & Odorless \\
\hline General Analysis & Brownish with White Specks & Odorless & Brown and White Specks & Odorless \\
\hline
\end{tabular}


Table 3. Density and $\mathrm{pH}$ of the 2 tablets

\begin{tabular}{|c|c|c|c|c|}
\hline \multirow{4}{*}{ Trial } & \multicolumn{4}{|c|}{ Starch-based Tablets } \\
\hline & \multicolumn{2}{|c|}{$\begin{array}{c}\text { Swamp Taro-Based } \\
\text { Tablet }\end{array}$} & \multicolumn{2}{|c|}{$\begin{array}{c}\text { Cassava-Based } \\
\text { Tablet }\end{array}$} \\
\hline & \multicolumn{4}{|c|}{ Parameters } \\
\hline & Density (g/cc) & $\mathrm{pH}$ & Density $(\mathrm{g} / \mathrm{cc})$ & $\mathrm{pH}$ \\
\hline 1 & 1.33 & 6.0 & 1.34 & 6.0 \\
\hline 2 & 1.33 & 6.0 & 1.33 & 6.0 \\
\hline 3 & 1.5 & 6.0 & 1.34 & 6.0 \\
\hline Average & 1.39 & 6.0 & 1.34 & 6.0 \\
\hline
\end{tabular}

the average friability of the tablets is beyond the accepted friability standard for uncoated (Table 4 ) which signifies that the processed tablets failed the friability testing. Because generally, conventional compressed tablets should not lose less than $1.00 \%$ of their weight which is the considered acceptable percentage of friability. The two tablets have almost the same compressive strength, or the force at which the tablet will break or crack with a mean difference of $\pm 0.42 \mathrm{psi}$ (pounds per square inch). This data indicates that the two tablets have a very low compressive strength which is signified by the statement that standard hardness of most uncoated tablets should be not less than $40 \mathrm{~N} / \mathrm{cm}^{2}$, equivalent to $58.015 \mathrm{psi}^{4}$ as shown in Table 5 .

Table 4. Friability of the produced tablets

\begin{tabular}{|c|c|c|}
\hline Trials & $\begin{array}{c}\text { Swamp Taro Starch- } \\
\text { Based Tablet (\%) }\end{array}$ & $\begin{array}{c}\text { Cassava Starch- } \\
\text { Based Tablet (\%) }\end{array}$ \\
\hline 1 & 25.29 & 16.38 \\
\hline 2 & 21.65 & 16.88 \\
\hline 3 & 20.08 & 22.13 \\
\hline Average & $\mathbf{2 2 . 3 4}$ & $\mathbf{1 8 . 4 6}$ \\
\hline
\end{tabular}

\subsection{Disintegration Property ${ }^{5}$}

In this test, two (2) sets of environment were used; under stressed condition at Simulated Gastric Fluid and under stressed condition at Simulated Intestinal Fluid. All fluids were subjected to temperature range of $40.6^{\circ} \mathrm{C}-41.7^{\circ} \mathrm{C}$ which is the average body temperature range of chickens. The time at which the tablet totally disintegrated was recorded and the results are herein tabulated. It can be observed that the tablets have a high rate of disintegration, meaning, it takes a little time for the tablet to disintegrate in order to dissociate the active areca nut powder which will serve as anthelminthic. The standard acceptable time for uncoated tablets to disintegrate is not more than 45 minutes ${ }^{\underline{6}}$ which suggest that the disintegrating property of the produced tablets whether Swamp Taro or Cassava - based is high and it is within the acceptable limit. Moreover, it can also be observed from the data that the Cassava Starch-based Tablet (CSBT) has a lower time disintegrating on both simulated fluids than the Swamp Taro Starch-based Tablet (STSBT).

Statistical treatment of the disintegration data suggests that there is a significant difference in terms of disintegration time of the two produced tablets in (Table 6), in which case, the Cassava Starch-based tablet is more rapid in disintegrating regardless of Simulated fluid than the Swamp Taro Starch-based Tablet because the t-computed values of 14.420 and 4.616 are greater than the $t$-critical value of 4.303 at $95 \%$ confidence level with 2 degrees of freedom ( $t$-table.xls).

Table 5. Compressive strength of the produced tablets

\begin{tabular}{|c|c|c|}
\hline Trials & $\begin{array}{c}\text { Swamp Taro Starch- } \\
\text { Based Tablet (psi) }\end{array}$ & $\begin{array}{c}\text { Cassava Starch-Based } \\
\text { Tablet }(\mathbf{p s i})\end{array}$ \\
\hline 1 & 0.377 & 0.482 \\
\hline 2 & 0.583 & 0.419 \\
\hline 3 & 0.373 & 0.558 \\
\hline Average & $\mathbf{0 . 4 4 4}$ & $\mathbf{0 . 4 8 6}$ \\
\hline
\end{tabular}

Table 6. Disintegration time of the 2 tablets

\begin{tabular}{|l|c|c|c|}
\hline \multirow{2}{*}{$\begin{array}{l}\text { Tablet } \\
\text { Samples }\end{array}$} & \multirow{2}{*}{ Trials } & \multicolumn{2}{|c|}{$\begin{array}{c}\text { Simulated Conditions @ Chicken Body } \\
\text { Temp. }\end{array}$} \\
\cline { 3 - 4 } & & $\begin{array}{c}\text { Simulated } \\
\text { Gastric Fluid (s) }\end{array}$ & $\begin{array}{c}\text { Simulated Intestinal } \\
\text { Fluid (s) }\end{array}$ \\
\hline \multirow{3}{*}{ STSBT } & 1 & 418 & 572 \\
\cline { 2 - 4 } & 2 & 565 & 678 \\
\cline { 2 - 4 } & 3 & 618 & 718 \\
\hline \multirow{2}{*}{ Average Time } & 1 & 533 & $\mathbf{6 5 6}$ \\
\hline \multirow{3}{*}{ CSBT } & 2 & 417 & 317 \\
\cline { 2 - 4 } & 3 & 267 & 291 \\
\hline \multicolumn{2}{|l|}{ Average Time } & $\mathbf{2 9 5}$ & 249 \\
\hline
\end{tabular}

\section{Conclusion}

Based on the results of the study, the following conclusions are conveyed: Swamp Taro Starch and Cassava Starch when dried can be used as alternative starch additive in the manufacture of tablets for veterinary use. Brown with 
White Specks and Odorless is the color and odor of the produced tablet, respectively. The density of both tablets is almost the same; Cassava Starch Tablet (CST) is $1.34 \mathrm{~g} / \mathrm{cc}$ while Swamp Taro Starch Tablet (STST) is $1.39 \mathrm{~g} / \mathrm{cc}$ with a $0.05 \mathrm{~g} / \mathrm{cc}$ difference. Both tablets have a $\mathrm{pH}$ average of 6.0. Moreover, both are insoluble to most solvents, but slightly soluble in alcohol. The friability of both tablets is beyond the acceptable limit of $1.00 \%$, in which case, the processed tablets are somewhat friable. The compressive strength of the tablets is also almost the same at which CST has an average compressive strength of $0.486 \mathrm{psi}$, while STST has an average compressive strength of $0.444 \mathrm{psi}$ with a difference of \pm 0.042 psi which is below the acceptable hardness boundary of 58.015 psi. There is a significant difference in terms of disintegrating property of the Swamp Taro and Cassava Starch, implying that the Cassava starch-based Tablet is quicker in terms of disintegration than the Swamp Taro starch-based Tablet because the $\mathrm{t}$-computed values are 14.420 and 4.616 in Simulated Intestinal Fluid and Simulated Gastric Fluid, respectively, are greater than the $\mathrm{t}$-critical value of 4.303 at $95 \%$ confidence level with 2 degrees of freedom.

\section{References}

1. Augsburger LL. Knowledge-based systems and other ai applications for tableting. $3^{\text {rd }}$ edition. pharmaceutical dosage forms: Tablets. Baltimore. 2004; 2:1-71.

2. Pharmaceutical industry neglects developing countries [Internet]. [cited 2017 Jan 14]. Available from: www. dw.com/en/pharmaceutical-industry-neglects-developingcountries/a-16331939.

3. Anthelminthic Drugs [Internet]. [cited] 2013 May 30. Available from: https://www.slideshare.net/shrinathraman/ antihelminthic-drugs.

4. Gberindyer F, Onyeyili P, Bosha J. Quality control properties of some brands of veterinary Albendazole boluses common in Nigeria. Journal of Pharmacy and Pharmacology. 2014; 2(2):135-39.

5. Hoashi Y, Tozuka Y, Takeuchi H. Development of a novel and simple method to evaluate disintegration of rapidly disintegrating. Tablets. Chemical and Pharmaceutical Bulletin. 2013; 61(9):962-66. https://doi.org/10.1248/cpb. c13-00441

6. Ministry of Health. Official method: Determination of the disintegration time of tablets. 2nd Edition. Canada; 1989. 